\title{
Food site residence time and female competitive relationships in wild gray-cheeked mangabeys (Lophocebus albigena)
}

\author{
Rebecca L. Chancellor • Lynne A. Isbell
}

Received: 16 November 2008 /Revised: 15 May 2009 / Accepted: 31 May 2009/Published online: 26 June 2009

(C) The Author(s) 2009. This article is published with open access at Springerlink.com

\begin{abstract}
Authors of socioecological models propose that food distribution affects female social relationships in that clumped food resources, such as fruit, result in strong dominance hierarchies and favor coalition formation with female relatives. A number of Old World monkey species have been used to test predictions of the socioecological models. However, arboreal forest-living Old World monkeys have been understudied in this regard, and it is legitimate to ask whether predominantly arboreal primates living in tropical forests exhibit similar or different patterns of behavior. Therefore, the goal of our study was to investigate female dominance relationships in relation to food in gray-cheeked mangabeys (Lophocebus albigena). Since gray-cheeked mangabeys are largely frugivorous, we predicted that females would have linear dominance hierarchies and form coalitions. In addition, recent studies suggest that long food site residence time is another important factor in eliciting competitive interactions. Therefore, we also predicted that when foods had long site residence times, higher-ranking females would be able to spend longer at the resource than lower-ranking females. Analyses showed that coalitions were rare relative to some other Old World primate species, but females had linear dominance hierarchies. We found that, contrary to expectation, fruit was not associated with more agonism and did not involve long site residence times. However, bark, a food with a long site residence time and
\end{abstract}

Communicated by J. Setchell

R. L. Chancellor $\cdot$ L. A. Isbell

Department of Anthropology, University of California,

Davis, CA, USA

R. L. Chancellor $(\triangle)$

Gishwati Area Conservation Program, Great Ape Trust of Iowa,

P.O. Box 538, Gisenyi, Rwanda

e-mail: rlchancellor@ucdavis.edu potentially high resource value, was associated with more agonism, and higher-ranking females were able to spend more time feeding on it than lower-ranking females. These results suggest that higher-ranking females may benefit from higher food and energy intake rates when food site residence times are long. These findings also add to accumulating evidence that food site residence time is a behavioral contributor to female dominance hierarchies in group-living species.

Keywords Food site residence time .

Gray-cheeked mangabeys $\cdot$ Lophocebus albigena .

Female relationships $\cdot$ Kibale National Park

\section{Introduction}

Group living is often associated with feeding competition (Alexander 1974; Pulliam and Caraco 1984), the cost of which may not be evenly distributed among individuals within a group. In groups with linear dominance hierarchies, the distribution of the cost of feeding competition may be in part determined by rank, as high rank is often associated with greater feeding and foraging success and lower costs (Vehrencamp 1983). For example, in semi-freeranging adult female American bison (Bison bison), dominance rank correlates with fatness and with the weight of offspring at weaning (Vervaecke et al. 2005) and in small groups of wild blackbirds (Turdus merula), top-ranking individuals benefit from a greater increase in foraging success than bottom-ranking individuals (Smith et al. 2001). Because of the great energetic demands of gestation and lactation, differential female reproductive success in mammals is thought to result from differential access to food (Trivers 1972), Thus, in many mammals, the study of 
female social relationships has focused in particular on the association between dominance rank and feeding competition (e.g., macaques (Macaca fascicularis), van Schaik and van Noordwijk 1988; chamois (Rupicapra rupicapra rupicapra), Ingold and Marbacher 1991; mountain goats (Oreamnos americanus), Fournier and Festa-Bianchet 1995; elephants (Loxodonta africana), Archie et al. 2006; chimpanzees (Pan troglodytes), Murray et al. 2006). In group-living primates, high rank has been linked to better foraging efficiency (Range and Noë 2002), higher food and energy intake rates (e.g., Janson 1985; Saito 1996; Vogel 2005), and longer food site residence or handling time (e.g., Isbell et al. 1998; Pruetz and Isbell 2000; Mathy and Isbell 2001; Chancellor and Isbell 2008). High rank is also often associated with greater reproductive success (Dunbar 1980; Busse 1982; van Noordwijk and van Schaik 1987; Saito 1996; Pusey et al. 1997). A majority of the research on primates has been on Old World monkeys (e.g., van Schaik and van Noordwijk 1988; Borries 1993; Isbell and Pruetz 1998; Range and Noë 2002). Previous studies have found that, in cercopithecine primates such as macaques (Macaca spp.), baboons (Papio spp.), and vervets (Cercopithecus aethiops), frequent agonistic interactions between females result in stable linear dominance hierarchies that are maintained through alliances of female relatives (Walters and Seyfarth 1987; Chapais 1992). Closely related females provide support against more distantly related females, and matrilines of higher rank support each other in coalitions against matrilines of lower rank (Seyfarth 1980; Hausfater et al. 1982; Barton and Whiten 1993; Chapais et al. 1997).

With the exception of blue monkeys (Cercopithecus mitis; Cords 2000, 2002), studies of female relationships in African monkeys have largely been limited to the more terrestrial species living in more open habitats, e.g., vervets, patas monkeys (Erythrocebus patas), and baboons (Seyfarth 1976; Byrne et al. 1989; Isbell and Pruetz 1998; Silk et al. 1999). A growing number of field studies provide evidence, however, that ecology influences female competitive relationships more than phylogeny (Mitchell et al. 1991; Isbell and Pruetz 1998; Boinski et al. 2002), and it is legitimate to ask whether predominantly arboreal primates living in tropical forests exhibit similar or different patterns of behavior. For example, dense foliage or narrow branch substrates within tree canopies could influence the rate of agonistic interactions or the coordination of coalitions. Evidence that this might be the case in tropical forests comes from a study of chacma baboons (Papio cynocephalus ursinus) living in a woodland habitat. Even in this woodland habitat, which likely has greater visibility than most tropical forests, reduced visibility limited the ability of higher-ranking individuals to scan or to control food patches that lower-ranking individuals occupied (Ron et al. 1996).
Authors of current socioecological models propose that food distribution affects female social relationships in that spatially clumped food resources, such as fruit, result in strong dominance hierarchies and favor coalition formation with female relatives (Wrangham 1980; van Schaik 1989; Sterck et al. 1997; Koenig and Borries 2006). In other highly frugivorous species, larger groups also travel farther per day than smaller groups, suggesting that feeding competition imposes increased costs in larger groups (Isbell 1991; Chapman et al. 1995; Janson and Goldsmith 1995). Group-adjusted daily travel distance in frugivorous primates is also typically associated with clearly defined female dominance hierarchies (Isbell 1991). There is increasing evidence, however, that another relevant characteristic of foods, at least in terms of female dominance relationships within groups, is depletion time. Foods that are depleted slowly can be clumped or widely dispersed but, more importantly, they appear to be more usurpable than foods depleted quickly because individuals spend more time at these foods, and usurpability favors agonistic interactions that allow observers to detect dominance hierarchies (Isbell et al. 1998; Isbell and Young 2002). Foods at which individuals spend a long time also most likely reflect high resource value since the amount of time spent at a resource may be an index of its value to the individual (Harcourt and Stewart 2007). Increasingly, studies are finding that larger foods (Mathy and Isbell 2001; Chancellor and Isbell 2008; Gemmill and Gould 2008) or foods with longer site residence times (Post et al. 1980; Janson 1990; Isbell et al. 1998; Pruetz and Isbell 2000) are more usurpable and elicit more aggression.

In a study of yellow baboons ( $P$. cynocephalus cynocephalus), high-ranking individuals in general were found to have longer feeding bouts than low-ranking individuals. Feeding bouts of high-ranking individuals were also less likely to be aggressively interrupted, and those individuals whose bouts were interrupted most had the shortest mean feeding bout durations (Post et al. 1980). In another study on vervets, higher rank was correlated with longer mean time spent at food sites (Isbell et al. 1999). In experiments with captive rhesus macaques (Macaca mulatta), foods with longer handling times elicited more aggression, and higher-ranking individuals were more likely to get those foods (Chancellor and Isbell 2008).

In this study, our goal was to extend our understanding of the ecology of female social relationships by specifically investigating the potential for a temporal characteristic of food, food site residence time, to affect female dominance relationships, in a tropical forest-dwelling and largely arboreal Old World monkey species, gray-cheeked mangabeys (Lophocebus albigena). Gray-cheeked mangabeys have been the subjects of numerous studies in Kibale National Park, Uganda, over many years (e.g., Waser 1977; 
Freeland 1979; Olupot et al. 1998; Lambert et al. 2004). Like most open-country cercopithecines, gray-cheeked mangabeys live in multimale/multifemale social groups. Females make up the stable core of the group whereas males disperse (Waser 1975; Olupot and Waser 2001). Although ecological and socioecological studies on feeding, ranging, and activity patterns have been conducted on gray-cheeked mangabeys (e.g., Waser 1978; Freeland 1979; Olupot et al. 1998; Olupot and Waser 2001), virtually nothing is known about competitive relationships between females within groups.

Mangabeys are predominantly frugivorous (Waser 1977), and larger groups of mangabeys (those over 15 individuals) travel farther per day than smaller groups (Waser 1977). Since fruits are often considered clumped and a clumped food distribution has often been assumed to be the underlying ecological cause of both adjustments of daily travel distance based on group size and obvious dominance relationships among females, we predicted the following in gray-cheeked mangabeys:

1. Females have agonistic interactions frequent enough for observers to detect dominance hierarchies.

2. Females form coalitions, a prediction of socioecological models when females have linear dominance hierarchies.

However, since we are also concerned here with usurpability and fruits are often large, with long residence times (at least relative to arthropods), we predicted that:

3. Food sites of different food types have different residence times, depending on resource value and consumption or processing time, e.g., fruit sites have longer residence times than leaf sites, and leaf sites have longer residence times than arthropod sites.

4. Food sites with long residence times are more associated with aggression than food sites with short residence times.

5. Higher-ranking females feed longer at food sites with longer residence times.

\section{Methods}

Study site and subjects

We conducted this project in the Kanyawara study area of the semilogged moist evergreen forest of Kibale National Park $\left(766 \mathrm{~km}^{2}\right)$, Uganda $\left(0^{\circ} 34^{\prime} \mathrm{N}, 30^{\circ} 21^{\prime} \mathrm{W}\right)$, located near the foothills of the Rwenzori Mountains (Waser and Floody 1974; Chapman et al. 1997). The area has a mean annual rainfall of 1,778 mm (1990-1998) and a mean daily minimum and maximum temperature of $15.5^{\circ} \mathrm{C}$ and $23.7^{\circ} \mathrm{C}$, respectively (Chapman and Chapman 2000).

We collected data on five study groups (BT1, BT2, LC, $\mathrm{CC}, \mathrm{MK}$ ) that have been followed at least once a month since the mid-1990s. We chose the groups for their home range locations, number of females, and the relative ease with which we could follow females and identify them by their natural markings. All groups were equally well habituated, allowing observations as close as $2 \mathrm{~m}$. Since gray-cheeked mangabeys are primarily arboreal, all groups spent most of their time in the canopy but all groups occasionally came to the ground to forage, drink, travel, etc. Group sizes ranged between ten and 21 individuals and consisted of between four and seven adult females, one and nine adult males, and three and ten immature individuals (group sizes: $\mathrm{BT} 1=10-16 ; \mathrm{BT} 2=12-15 ; \quad \mathrm{LC}=17-21$; $\mathrm{CC}=14-17 ; \mathrm{MK}=12-16)$. The mangabeys at Kibale occupy a variety of habitats, from undisturbed to lightly and heavily disturbed forest (Skorupa 1988). The study groups lived primarily within lightly to moderately logged forest except for $\mathrm{CC}$, which ranged primarily in unlogged forest. Home ranges were between 54 and 87 ha $(\mathrm{BT} 1=66$; $\mathrm{BT} 2=79 ; \mathrm{LC}=87 ; \mathrm{CC}=61 ; \mathrm{MK}=54)$, estimated by counting the number of $50 \times 50-\mathrm{m}$ quadrats entered at least once (e.g., Isbell 1983) from global positioning system recordings of group movements every half-hour during sampling days (avg 3 days per group per month).

\section{Data collection}

We collected data between January 2004 and August 2005. We could identify all adult and subadult females individually by July 2004. Adult females were those exhibiting visible sexual swellings and subadult females were similar size to adults that began to exhibit visible sexual swellings during the study period. In each group, we began systematic data collection when we could identify all adult and subadult females $(N=26$; $\mathrm{BT} 1=5$; $\mathrm{BT} 2=4 ; \mathrm{LC}=7 ; \mathrm{CC}=5 \mathrm{MK}=5$ ). We conducted an average of three all-day group follows per month on each group (mean (range): $\mathrm{BT} 1=3(2-5) ; \mathrm{BT} 2=3(0-8) ; \mathrm{LC}=5(2-7)$; $\mathrm{CC}=3(2-5) ; \mathrm{MK}=3(1-5))$. We sampled the groups using predetermined random sampling without replacement. Since mangabeys have fairly large home ranges, if we could not find a group, we sampled another group whose location was known. We sampled each female in the group at least once for a continuous 30-min focal during each allday group follow. Because individual females could be difficult to find, we determined the sampling order within groups by locating the first female not yet sampled during the sampling day. As soon as the female was located, we began the 30-min focal. If a female went out of view, we attempted to locate her for $20 \mathrm{~min}$. If she was found again 
within $5 \mathrm{~min}$, we continued the sampling. If she was found after $5 \mathrm{~min}$, we discounted the time while out of sight and followed her for a total of 30 focal minutes.

We collected behavioral data using a combination of focal and all occurrences sampling. We determined dominance relationships by the direction of agonistic dyadic interactions involving females, including chases (i.e., aggressively pursuing another), approach-avoids (i.e., moving away from another who is approaching), supplants (i.e., taking the place of another), physical contacts (e.g., biting, tail-pulling, pushing), and nonphysical threats (e.g., facial threats). We used only interactions in which we could determine a clear aggressor in the dominance hierarchy calculations. A coalition occurred when one female actively supported another female in an agonistic interaction with a third party. The data set consists of $532 \mathrm{~h}$ of focal follows of 26 females (total hour (mean hour per female): $\mathrm{BT} 1=98$ (20); $\mathrm{BT} 2=74$ (19); $\mathrm{LC}=$ 139 (20); $\mathrm{CC}=114$ (23); $\mathrm{MK}=107$ (21)).

One way of assessing depletion time of food is to consider food site residence time. As per Isbell et al. (1998), we recorded food site residence time using the behavior of females during focal samples. We recorded food site residence time by noting the duration of time per food site, where we defined a food site as any spot at which an individual stopped to eat food and which was separated by other food sites by hind limb locomotion (i.e., both hind limbs had to move; an animal just turning itself or taking a step with one foot to reach for food was not counted as hind limb locomotion). Since it is unclear whether or not the food was actually depleted before the animal moved on, we amend the original term depletion time (Isbell et al. 1998) to residence time. In addition, we recorded the food items eaten at each food site. We divided food items into five general categories for analyses: fruit (fruit and seeds), arthropods, leaves, flowers, and bark (bark cambium and pith). We excluded fungi food sites (i.e., mushrooms, lichen) from analyses because they were eaten only rarely and not by all focal females or groups.

\section{Statistical analyses}

Dominance analyses included agonistic interactions from both focal and all occurrences sampling. We used a Bayesian analysis to determine female dominance hierarchies. Similar to nonparametric methods, Bayesian analysis determines the most likely rank orderings. Unlike nonparametric methods, it provides additional measures of certainty by generating the posterior probabilities of those orderings based on prior probability distributions. This makes it possible to find out if there are several plausible hierarchies with similar posterior probabilities. More traditional nonparametric methods only produce a single "best" hierarchy, with no added information about other plausible hierar- chies. Therefore, they provide no information regarding uncertainty of the "best" hierarchy (i.e., how much better it is than the next best hierarchy; Gill 2002; Adams 2005).

We based the Bayesian models on Adams (2005) and personal communication with Adams, and they are available upon request. Adam's model is a Bayesian version of the Bradley-Terry model (Bradley and Terry 1952). Under the Bradley-Terry model, (1) the number of wins by animal $i$ in $n$ contests with animal $j$ is a binomial random variable with parameters $n$ and $p_{i j}$; and (2) the logit of $p_{i j}$ is equal to the difference in dominance indices between the animals, $d_{i}-d_{j}$. Adams' model uses a normal distribution centered at zero as the prior for each dominance index $d$.

After checking for intransitivities, we conducted analyses in WinBUGS 1.4 (Spiegelhalter et al. 2003), a software program that uses Markov chain Monte Carlo (MCMC) simulation to fit the Bayesian models (Adams 2005). The prior distribution for dominance indices was a normal distribution with mean of zero and variance chosen for each group to ensure adequate mixing of the Markov chain. We aimed at using a prior that was narrow enough for the chain to mix without narrowing so much as to constrain the posterior. Therefore, our smallest prior variance used (variance $=1 / 0.04=25$, for groups LC and MK) still provided a broad enough prior distribution to allow for adequate spread of posterior dominance indices, especially for these relatively small dominance hierarchies. For groups LC and MK, we chose a variance of 25 because when the prior had a variance $>25$, the Markov chain did not mix well, and we were not able to get information about the posterior. In order to test the sensitivity of the results to the priors, we ran two of the groups, CC and BT2, with both the largest $(1,000)$ and smallest $(25)$ prior variances used in the analyses, and found that reducing the variance to $25 \mathrm{did}$ not change the most probable dominance hierarchies. For each group, we discarded the first 500 MCMC iterations (i.e., the "burn-in" portion of the Markov chain) to ensure convergence to a suitably stationary posterior distribution before drawing the 10,000 samples used to find the posterior probability of rank orderings (see also Adams 2005). We used CodaReader 1.01 (Adams 2005) to find the posterior probability of rank orderings.

For comparability with more traditional measures of dominance, we also checked the percentage of reversals and the directional consistency index (DC index), which ranges from 0 to 1 and is calculated by $(H-L) /(H+L)$, where $H$ is the total number of agonistic interactions in the direction of higher frequency and $L$ is the total number of agonistic interactions in the direction of lower frequency (e.g., van Hooff and Wensing 1987; Archie et al. 2006), using MatMan 1.1 (Noldus Information Technology b.v., The Netherlands). 
The DC index and the percentage of reversals are particularly useful when groups are smaller than six, when tests based on the Landau linearity index $(h)$ or de Vries's corrected linearity index $\left(h^{\prime}\right)$ have diminished statistical power (Appleby 1983; Isbell and Young 2002; Archie et al. 2006). In addition, we calculated de Vrie's corrected linearity index (ranging from 0 to 1 ) for $\mathrm{LC}$, the group in which there were enough females $(N=7)$ to do the test.

To test whether rank and different food types (fruit, leaves, bark, arthropods, flowers) predicted different food site residence times, we fitted a mixed-effects linear model with random effects for group and female within group and fixed effects for rank, food type, and the interaction between rank and food type. The unit of observation was food site visited by a female during focal sampling. We logtransformed the food site residence time data because of a right-tailed skew. We used the hierarchy for each group having the largest posterior probability to assign rank.

We conducted all analyses except the dominance matrices using the software program JMP 7 (SAS Institute Inc., Cary, NC, USA). We set statistical significance at $P=0.05$ and all tests were two-tailed. Throughout the manuscript, the means and standard deviations are provided unless otherwise noted.

\section{Results}

Dominance hierarchies

During 532 focal hours, we observed a total of 301 dyadic agonistic interactions between females $(\mathrm{BT} 1=70 ; \mathrm{BT} 2=46$; $\mathrm{LC}=72 ; \mathrm{CC}=48 ; \mathrm{MK}=65$; events per female per focal hour: $\mathrm{BT} 1=0.14 ; \mathrm{BT} 2=0.16 ; \mathrm{LC}=0.07 ; \mathrm{CC}=0.08 ; \mathrm{MK}=$ 0.12 ). The most frequent agonistic interaction was approachavoid (44\%), followed by supplant (35\%), chase (14\%), physical contact (4\%), and nonphysical threat $(2 \%)$. Food was the target of more than half (55\%) of all observed agonistic interactions.

As predicted, females in all five groups could be placed into linear dominance hierarchies using both the Bayesian analyses and the nonparametric analyses. Figure 1 shows the posterior probabilities, for the Bayesian analyses, of the most likely dominance rankings, from highest to lowest, for each group within a $95 \%$ credibility set. The posterior probabilities varied by group. For example, the posterior probability for the most likely rank ordering for the MK group was $98 \%$, while the most likely rank ordering for the LC group was $42 \%$. The lower probabilities in LC, in particular, may be due to fewer interactions being observed between some dyads.

For each group, the nonparametric method produced the dominance hierarchy having the largest posterior probability under the Bayesian method. This was most likely because agonistic interactions among females were strongly unidirectional and the number of reversals was relatively low, indicating that most interactions followed the direction of the hierarchy (LC group, directional consistency index 0.97 , reversals $2 \%$; CC group, directional consistency index 0.82 , reversals $9 \%$; MK group, directional consistency index 0.88 , reversals $6 \%$; BT1 group, directional consistency index 0.96 , reversals 2\%; BT2 group, directional consistency index 0.83 , reversals $9 \%$ ). LC, the group in which there were enough females to calculate de Vrie's linearity test, showed significant linearity $\left(h^{\prime}=0.82, p=0.04\right)$.

\section{Third-party interventions and female coalitions}

During focal hours, we observed five agonistic dyadic interactions between females that led to intervention by a third party ( $2 \%$ of all agonistic interactions). In two cases, the third party was another female and in the other cases the third party was a juvenile female twice and a juvenile male once. Outside of focal hours, we observed only one other agonistic interaction between females that led to intervention by a third female.

Although females formed obvious linear dominance hierarchies, coalitions between females were infrequent. During focal hours, females formed 12 coalitions, including the two mentioned above. Outside of focal hours, we observed ten additional female coalitions, including the one mentioned above. Half of female coalitions (11 of 22) were directed towards adult males. Females formed coalitions most often with females within one rank distance of their own (13 of 18 coalitions (72\%)). At least seven (32\%) of the 22 coalitions were over food.

Food site residence time, rank, and food type

We recorded 10,525 food sites for which we had complete residence times (range 290-614 sites per female). Of those sites, over half involved fruit (52\%). Arthropods were second with $30 \%$, followed by leaves $(8 \%)$, flowers $(7 \%)$, and, finally, bark (3\%). Overall, mean food site residence time was $66 \pm 87 \mathrm{~s}$.

The independent effect of food type significantly predicted food site residence time $\left(F_{4}, 10,447=65.93\right.$, $P<0.0001)$. The mean food site residence time for bark $(150 \pm 206 \mathrm{~s})$, the food type with the longest residence time, was over twice that of arthropods ( $55 \pm 60 \mathrm{~s})$, the food type with the shortest residence time (Table 1). As predicted, the food types' mean residence times closely corresponded to the percentages of their food sites contested (Table 1; Fig. 2). Overall, rank did not significantly predict food site residence time $\left(F_{1,37.71}=0.24, P=0.6\right)$ nor did the interac- 


\begin{tabular}{|lccccccc|}
\hline $\mathbf{L C}$ & $\mathrm{NG}$ & $\mathrm{MB}$ & $\mathrm{NT}$ & $\mathrm{NS}$ & $\mathrm{KI}$ & $\mathrm{NM}$ & $\mathrm{KO}$ \\
$\mathrm{NG}$ & $*$ & 1 & 1 & 0 & 0 & 1 & 3 \\
$\mathrm{MB}$ & 0 & $*$ & 2 & 0 & 2 & 2 & 8 \\
$\mathrm{NT}$ & 0 & 0 & $*$ & 10 & 5 & 4 & 3 \\
$\mathrm{NS}$ & 0 & 0 & 0 & $*$ & 16 & 11 & 17 \\
$\mathrm{KI}$ & 0 & 0 & 0 & 0 & $*$ & 3 & 3 \\
$\mathrm{NM}$ & 0 & 0 & 0 & 1 & 1 & $*$ & 21 \\
$\mathrm{KO}$ & 0 & 0 & 0 & 0 & 0 & 0 & $*$ \\
\hline
\end{tabular}

\section{$\underline{\text { Rank orderings }}$}

pp

$\mathrm{NG}>\mathrm{MB}>\mathrm{NT}>\mathrm{NS}>\mathrm{KI}>\mathrm{NM}>\mathrm{KO}$

$42 \%$

$\mathrm{NG}>\mathrm{MB}>\mathrm{NT}>\mathrm{NS}>\mathrm{NM}>\mathrm{KI}>\mathrm{KO} \quad 28 \%$

$\mathrm{MB}>\mathrm{NG}>\mathrm{NT}>\mathrm{NS}>\mathrm{KI}>\mathrm{NM}>\mathrm{KO} \quad 9 \%$

$\mathrm{NG}>\mathrm{NT}>\mathrm{MB}>\mathrm{NS}>\mathrm{KI}>\mathrm{NM}>\mathrm{KO}$

$6 \%$

$\mathrm{MB}>\mathrm{NG}>\mathrm{NT}>\mathrm{NS}>\mathrm{NM}>\mathrm{KI}>\mathrm{KO} \quad 6 \%$

$\mathrm{NG}>\mathrm{NT}>\mathrm{MB}>\mathrm{NS}>\mathrm{NM}>\mathrm{KI}>\mathrm{KO} \quad 5 \%$

\begin{tabular}{|lccccc|}
\hline $\mathrm{CC}$ & $\mathrm{MY}$ & $\mathrm{BO}$ & $\mathrm{KU}$ & $\mathrm{KE}$ & $\mathrm{MZ}$ \\
$\mathrm{MY}$ & $*$ & 6 & 2 & 5 & 7 \\
$\mathrm{BO}$ & 0 & $*$ & 7 & 12 & 8 \\
$\mathrm{KU}$ & 0 & 1 & $*$ & 3 & 5 \\
$\mathrm{KE}$ & 0 & 0 & 1 & $*$ & 4 \\
$\mathrm{MZ}$ & 1 & 0 & 3 & 0 & $*$ \\
\hline
\end{tabular}

\begin{tabular}{lr} 
Rank orderings & pp \\
\hline $\mathrm{MY}>\mathrm{BO}>\mathrm{KU}>\mathrm{KE}>\mathrm{MZ}$ & $51 \%$ \\
$\mathrm{MY}>\mathrm{BO}>\mathrm{KE}>\mathrm{KU}>\mathrm{MZ}$ & $24 \%$ \\
$\mathrm{MY}>\mathrm{BO}>\mathrm{KU}>\mathrm{MZ}>\mathrm{KE}$ & $18 \%$ \\
$\mathrm{MY}>\mathrm{BO}>\mathrm{KE}>\mathrm{MZ}>\mathrm{KU}$ & $2 \%$
\end{tabular}

Fig. 1 The most likely dominance matrices for each group based on Bayesian analyses, accompanied by the posterior probabilities (pp) of the most likely rank orderings within the $95 \%$ credibility set. For example, the probability of the most likely rank ordering for LC is $42 \%$, followed by the second most likely rank ordering, $28 \%$, and the next $9 \%$

tion between rank and food type $\left(F_{4,10372}=1.84, P=0.1\right)$. This was largely due to a poor rank effect on food site residence times for fruits, flowers, and leaves. In contrast, there was a significant positive relationship between rank and bark site residence time (Table 2). As rank increased, bark site residence time increased, so that higher-ranking females fed for longer periods at bark sites than lowerranking females. For example, the estimate showed that a female of rank 1, on average, spent 1.5 times longer feeding at a bark site than a female of rank 7 (Fig. 3). There was also a small but significant negative relationship between

\begin{tabular}{|lccccc|}
\hline BT1 & KS & KG & KB & KK & MK \\
KS & $*$ & 9 & 13 & 11 & 8 \\
KG & 0 & $*$ & 19 & 12 & 6 \\
KB & 0 & 0 & $*$ & 7 & 6 \\
KK & 0 & 0 & 0 & $*$ & 5 \\
MK & 0 & 0 & 0 & 2 & $*$ \\
\hline
\end{tabular}

Rank orderings

pp

$\mathrm{KS}>\mathrm{KG}>\mathrm{KB}>\mathrm{KK}>\mathrm{MK} \quad 88 \%$

$\mathrm{KS}>\mathrm{KG}>\mathrm{KB}>\mathrm{MK}>\mathrm{KK} \quad 12 \%$

\begin{tabular}{|lcccc|}
\hline BT2 & KM & KR & BA & BR \\
KM & $*$ & 6 & 11 & 18 \\
KR & 4 & $*$ & 9 & 6 \\
BA & 1 & 0 & $*$ & 13 \\
BR & 0 & 0 & 1 & $*$ \\
\hline
\end{tabular}

Rank orderings

$\mathrm{KM}>\mathrm{KR}>\mathrm{BA}>\mathrm{BR} \quad 64 \%$

$\mathrm{KR}>\mathrm{KM}>\mathrm{BA}>\mathrm{BR} \quad 36 \%$

\begin{tabular}{|lccccc|}
\hline MK & KT & KD & NK & NB & IJ \\
KT & $*$ & 8 & 6 & 4 & 8 \\
$\mathrm{KD}$ & 0 & $*$ & 14 & 2 & 5 \\
$\mathrm{NK}$ & 0 & 3 & $*$ & 10 & 9 \\
$\mathrm{NB}$ & 0 & 0 & 1 & $*$ & 14 \\
$\mathrm{IJ}$ & 0 & 1 & 0 & 0 & $*$ \\
\hline
\end{tabular}

\section{Rank orderings $\quad$ pp}

$\mathrm{KT}>\mathrm{KD}>\mathrm{NK}>\mathrm{NB}>\mathrm{IJ} \quad 98 \%$

Fig. 1 (continued)

rank and arthropod site residence time (Table 2). As rank increased, arthropod site residence time decreased, so that higher-ranking females fed for shorter periods at arthropod sites than lower-ranking females. For example, the estimate showed that a female of rank 1 , on average, spent only 0.88 times as long feeding at an arthropod site than a female of rank 7. In addition, there was a small, though not significant, negative relationship between rank and fruit site residence time (Table 2).

Bark cambium or pith was eaten from Celtis africana, Blighia unijugata, Trema guineensis/orientalis, Linociera johnsonii. Pseudospondias micocarpa, Millettia dura, Macaranga schweinfurthii, and Prunus (Pygeum) africana. 
Table 1 The percentage of sites contested and the mean site residence time for each food item

\begin{tabular}{llll}
\hline Food item & Total no. of sites & \% sites contested $(95 \% \mathrm{CI})$ & Mean site residence time (s; 95\% CI) \\
\hline Fruit & 5,504 & $1.7(1.3,2.0)$ & $62(60,64)$ \\
Arthropods & 3,177 & $0.9(0.5,1.2)$ & $56(53,58)$ \\
Leaves & 843 & $1.4(0.6,2.2)$ & $80(74,87)$ \\
Flowers & 676 & $2.2(1.1,3.4)$ & $86(78,94)$ \\
Bark & 325 & $5.5(3.0,8.1)$ & $150(127,172)$ \\
\hline
\end{tabular}

Collectively, these trees are not rare. Enumerations conducted in 1992, for example, showed that they occurred at a density of approximately 45 stems per hectare (Chapman et al. 1997). As another way to examine the link between food site residence time and competition between females, we compared food site residence time and aggression at bark and fruit sites in C. africana, the most common tree species from which mangabeys ate bark cambium $(49 \%$ of total bark sites recorded). In addition to its continually available bark, C. africana produces fruits at low levels throughout the year (Struhsaker 1997). Despite the availability of both bark and fruits, however, aggression occurred at $9.6 \%$ of bark sites but only $0.3 \%$ of fruit sites. This difference between bark and fruit in the percentage of aggression closely parallels the difference between bark and fruit in residence time: the average residence time in $C$. africana was $214 \pm 124 \mathrm{~s}$ for bark sites vs $43 \pm 15 \mathrm{~s}$ for fruit sites.

\section{Discussion}

Female dominance relationships

Female agonism was frequent enough in gray-cheeked mangabeys to detect linear dominance hierarchies in all five study groups. Most agonistic interactions between females were nonaggressive approach-avoids or supplants. This suggests that the females in the study groups had relatively well-established dominance hierarchies in which they could assess one another's contest ability without escalation (Parker 1974).

Both the Bayesian analyses and the nonparametric analyses revealed the same "best" rank orderings for all groups. This was most likely because agonistic interactions among females were strongly unidirectional and the number of reversals was relatively low indicating that most interactions followed the direction of the hierarchy. In spite of this, the posterior probabilities from the Bayesian analyses varied by group. In some groups, the $95 \%$ credibility set contained several hierarchies, while in other groups it contained only one or two. For example, the "best" hierarchy for LC had only a $42 \%$ posterior probability and the $95 \%$ credibility set contained six possible hierarchies, while the "best" hierarchy for MK had a $98 \%$ posterior probability and contained only one hierarchy in the $95 \%$ credibility set. Therefore, the Bayesian analysis revealed that there is more confidence in the hierarchy of the MK females than that of the LC females. The lower probabilities in LC, in particular, may be due to fewer interactions being observed between some dyads.

Gray-cheeked mangabeys in Kibale appear to have somewhat higher agonistic rates than several populations of guenons, similar rates to two populations of macaques, and lower rates than one population of baboons, a species to which mangabeys are relatively closely related (e.g., Harris 2000; Tosi et al. 2003; Fig. 4). However, given the limitations of a small sample size (e.g., baboon populations may vary in their coalition probabilities) and different methodologies used (e.g., different studies may use different kinds of interactions), we note only that the agonistic rates of gray-cheeked mangabeys are nestled among those of other papionins, the clade to which mangabeys belong.

\section{Third-party interventions and female coalitions}

Agonistic interactions between females that led to intervention by a third party ( $2 \%$ of total agonistic interactions) were uncommon. In a study of yellow baboons, a closely related species (e.g., Harris 2000; Tosi et al. 2003), 4-6\% of female agonistic interactions led to intervention by third parties, and $1-4 \%$ of those third parties were female (Silk et al. 2004). Coalitions between females were also infrequent, but when females did form coalitions, they formed them most often with females of similar rank to themselves, and half were directed against adult males. Despite the prediction of socioecological models of female relationships that female coalitions co-occur with clearly defined dominance hierarchies, other studies of Old World monkeys have also found coalition formation among females to be rare (blue monkeys, Cords 2002) or nonexistent (chacma baboons, Barrett et al. 1999). The infrequency of female coalitions in other well-studied cercopithecine primates suggests that they may not be as important to female intragroup feeding competition as socioecological models predict. However, Cords (2002) suggested that, even when rare, the occurrence of coalitions might still be important in influencing behavior, specifically competition for food. As 


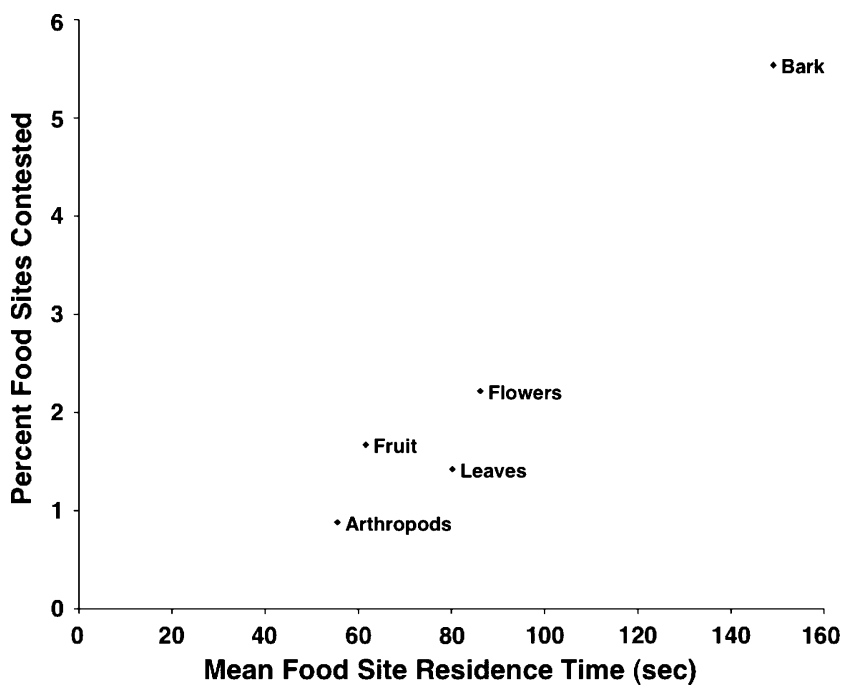

Fig. 2 The relationship between the mean food site residence time and the percentage of contested food sites per food item

socioecological models predict (Wrangham 1980; van Schaik 1989; Isbell 1991; Sterck et al. 1997), food was also the target of more than half of all observed agonistic interactions between females, and the target of at least $32 \%$ of female-female coalitions.

Food site residence time and female dominance relationships

Mangabeys are predominantly frugivorous; fruits constituted over half of their diet. Fruits are often considered

Table 2 The parameter estimates from the mixed-effects linear regression model examining the effects of rank, food type, and the interaction between the two on log-transformed food site residence time

\begin{tabular}{lccrc}
\hline Term & Estimate & SE & $t$ ratio & Prob $>|t|$ \\
\hline Intercept & 3.91 & 0.07 & 54.00 & $<0.0001$ \\
Rank & -0.01 & 0.02 & -0.49 & 0.63 \\
Arthropods & -0.28 & 0.02 & -12.36 & $<0.0001$ \\
Bark & 0.54 & 0.05 & 10.93 & $<0.0001$ \\
Flowers & 0.07 & 0.04 & 1.85 & 0.06 \\
Fruit & -0.28 & 0.02 & -14.20 & $<0.0001$ \\
Arthropods $\times$ rank & 0.03 & 0.01 & 2.20 & 0.03 \\
Bark $\times$ rank & -0.06 & 0.03 & -2.16 & 0.03 \\
Flowers $\times$ rank & 0.004 & 0.02 & 0.17 & 0.87 \\
Fruit $\times$ rank & 0.02 & 0.01 & 1.86 & 0.06 \\
\hline
\end{tabular}

The interactions between bark and rank and arthropods and rank had a significant effect on food site residence time $(N=10,525)$. Negative estimates for rank and interactions with rank reflect the fact that lower values are assigned to higher-ranking females (i.e., the highest-ranking female in a group is ranked 1). The model $R^{2}$ was 0.04 , and the percentage of variance explained was $0.8 \%$ for female within group, $1.0 \%$ for group, and $98.2 \%$ for residual

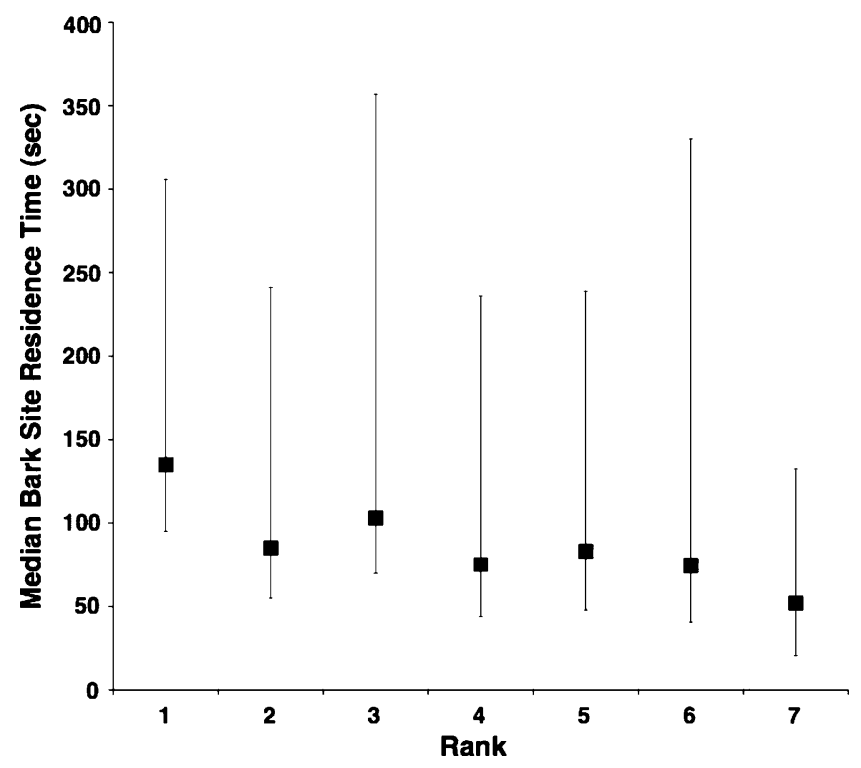

Fig. 3 Female rank by median bark food site residence time $(N=325)$. The highest-ranking female is assigned a rank of 1 and the lowestranking female, 7. Squares represent the medians, and bars and whiskers represent the $25 \%$ and $75 \%$ quartiles

clumped and worth fighting over, and their clumped distribution has often been thought to be responsible for female dominance hierarchies (e.g., Wrangham 1980; van Schaik 1989). However, recent studies have found that young leaves are also often clumped (e.g., Snaith and Chapman 2005; Koenig and Borries 2006). Surprisingly, female mangabeys did not interact agonistically over fruits (or leaves) more than other food types and high-ranking females did not spend more time than lower-ranking females at food sites with fruits, flowers, or leaves. Instead, agonistic interactions occurred most predictably when females ate bark, and higher-ranking females spent more time at bark sites than lower-ranking females.

Although our goal was not to examine the spatial distribution or abundance of different food types in relation to female competition, we suggest that residence time at bark food sites was not spuriously correlated with aggression via the clumped spatial distribution or rarity of bark for three reasons. First, although bark was eaten rarely compared to fruits and leaves, it appears to be a readily available food type. The mangabeys fed on bark cambium or pith from several species of trees and the bark could be both clumped and dispersed. Although some bark trees occur at low densities in the Kanyawara area (e.g., Premna angolensis: one to two stems per hectare), others are relatively common (e.g., C. africana: up to 19 stems per hectare; Struhsaker 1975; Chapman et al. 1997; Isbell, unpublished data). Collectively, however, the tree bark from which mangabeys eat occurs at a fairly high density in Kibale. Second, the distribution of bark varies. Within a given tree, for example, bark cambium from the trunk and 


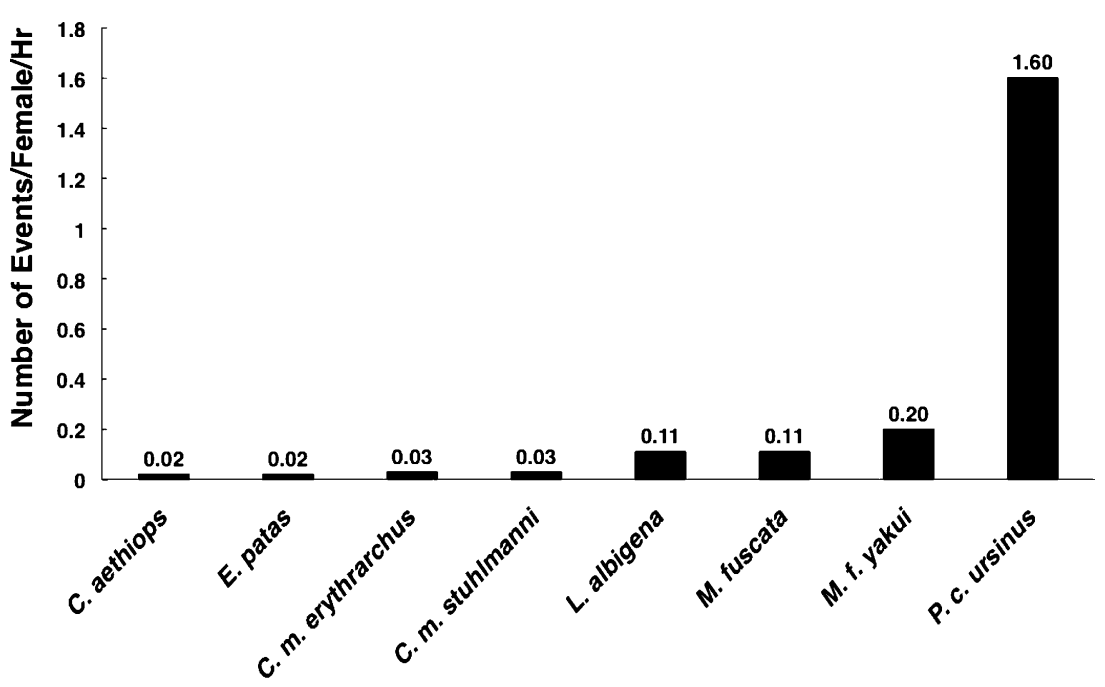

Study Species

Fig. 4 Agonistic rates for different populations of female Old World monkeys based on either total focal or total observation hours. See text for caveats related to the interpretation of these comparative data. Sources: (Cercopithecus aethiops and Erythrocebus patas, Isbell and
Pruetz 1998; Cercopithecus mitis erythrarchus, Payne et al. 2003; Cercopithecus mitis stuhlmanni, Cords 2000; Lophocebus albigena, this study; M. fuscata, Saito 1996; M. fuscata yakui, Hill and Okayasu 1995; P. cynocephalus ursinus, Barrett et al. 1999) large branches is clumped relative to pith from twigs within the canopy. More importantly, however, bark within the canopy is likely to be no more clumped than fruits, the foods that we expected females to compete over most because of their presumably clumped distribution. Finally, bark is continuously available.

Bark was the food that took the longest time to consume, probably because it requires time to prepare for eating. Live bark is often ripped off the tree in strips up to a meter long and then the cambium is removed with canines (e.g., C. africana trees), or bark is peeled back from twigs broken off of branches and then the pith is consumed (e.g., P. angolensis trees; Waser 1977; Olupot 1998; RLC, personal observation). A site may also yield multiple strips or twigs, allowing an individual to feed at the site for a long period of time. Given that there was greater competition over bark than over other food types, it is not surprising that high-ranking females spent more time than lower-ranking females at food sites with bark. Being able to spend longer periods at food sites may be energetically advantageous. Bark may be high in nutrients, including protein and soluble sugars (Rogers et al. 1994). According to Waser (1977), the bark of C. africana, a preferred bark source for the mangabeys in Kibale, is sweet. An individual that has to leave a site earlier than she otherwise would because of aggression will likely incur extra travel and search costs before finding another appropriate site, and higher-ranking individuals, by definition, are those that dispense the most and receive the least aggression. Our results add to accumulating evidence that food site residence time is a behavioral contributor to female dominance hierarchies (Isbell et al. 1998; Mathy and Isbell 2001; Vogel and Janson 2007; Chancellor and Isbell 2008). Similarly, in mountain gorillas (Gorilla gorilla beringei), dominant adult males are able to stay twice as long $(8.5 \mathrm{~min})$ at feeding spots than subordinate females (2.5-4.0 min; Fossey and Harcourt 1977). Being able to sit undisturbed while feeding may contribute to greater foraging efficiency or higher food and energy intake rates for high-ranking individuals.

Bark eating is a unique characteristic of mangabeys relative to other cercopithecines (C. mitis and Cercopithecus ascanius) in Kibale (Waser 1977; Lambert et al. 2004). Why do female mangabeys compete over bark? Even though bark makes up a small percentage of the mangabey diet, the evident competition over it suggests that it may be very important, perhaps as a fallback food when preferred foods are not available (Lambert et al. 2004). Bark has been argued to be an important fallback resource for gorillas $(G$. gorilla gorilla; Rogers et al. 1994), orangutans (Pongo pygmaeus; Knott 1998), and Barbary macaques (Macaca sylvanus; Menard and Qarro 1999). In mountain gorillas, aggression occurs over decaying wood (Harcourt and Stewart 2007), and it has recently been found to be a very important source of sodium in their diet (Rothman et al. 2006). Ultimately, aggression over bark sites in mangabeys may be a consequence of both long site residence times (making bark sites usurpable) and potentially high resource value (making them worth spending time on).

Interestingly, arthropods had the shortest residence times and were negatively associated with high rank. Many 
arthropods can be eaten very quickly because they are small, occur as solitary individuals, or have defenses that preclude continued feeding on them (e.g., Sillén-Tullberg and Leimar 1988; Krall et al. 1999; Eisner et al. 2000; Isbell and Young 2007). All of these characteristics may make arthropods difficult to usurp. Because arthropods are difficult to usurp, low-ranking individuals may make up for nutrients lost at bark sites by feeding longer at arthropod sites. However, with a valuable but nonusurpable food resource, a high-rank advantage might involve being able to harvest the prey more efficiently, and thus reducing site residence time, rather than being able to have a long site residence time. Rank advantages in foraging efficiency occur in other species. For example, higher-ranking female sooty mangabeys (Cercocebus torquatus atys) have a higher foraging efficiency than lower-ranking females (Range and Noë 2002). In capuchins (Cebus apella and Cebus capucinus) and Japanese macaques (Macaca fuscata), higher-ranking individuals have higher food and energy intake rates relative to lower-ranking individuals (Janson 1985; Saito 1996; Vogel 2005).

There are few studies that measure food site residence time using the movements of individuals. Comparable data in cercopithecines are only available thus far for vervets and patas monkeys, both of which are more terrestrial than gray-cheeked mangabeys. Mean food site residence time of female mangabeys (66 s) was more than twice that of vervets in Laikipia, Kenya (approximately $25 \mathrm{~s}$ ), and four times longer than that of patas monkeys, also in Laikipia (approximately $15 \mathrm{~s}$; L.A. Isbell, unpublished data). Vervets in Laikipia feed mainly on small fruits, leaves, flowers, and gum whereas patas monkeys feed mainly on gums and arthropods; neither species eats bark (Isbell 1998; Isbell et al. 1998). These data suggest that the foods of mangabeys have longer site residence times than those of both vervets and patas monkeys. The rate of agonism between female mangabeys is also higher (Fig. 4) which may be due to differences in food types consumed.

In summary, we found substantial support for basic socioecological theory, which predicts that social relationships of female animals are affected by ecological conditions of their foods, in gray-cheeked mangabeys, an arboreal forest-dwelling Old World monkey. Female graycheeked mangabeys engage in agonistic interactions more frequently over foods that are depleted slowly and this is associated with having clearly defined linear dominance hierarchies. Importantly, however, the critical food type was not fruit, which is the most frequently eaten, but bark, eaten far less but for much longer per site. The benefit of being a high-ranking female includes being able to feed longer at food sites that are more slowly depleted and to aggressively force lower-ranking females from foods with long site residence times because such foods are more usurpable and likely more valuable. Therefore, higher-ranking females may be able to obtain more foods and expend less energy to obtain those foods, in the short run gaining a greater net benefit from holding their higher positions and, in the long run, translating this benefit into relatively more offspring. These results add to growing evidence from other studies that a critical characteristic of food underlying agonistic social relationships in female animals is the length of time spent at a food resource.

Acknowledgments The Leakey Foundation and the University of California, Davis Department of Anthropology provided funding for this study. In Uganda, we thank the Office of the President, the Uganda National Council for Science and Technology, the Uganda Wildlife Authority, and the Makerere University Biological Field Station for permission to conduct research in Kibale National Park. We also thank C. Chapman for logistical support in the field, W. Olupot for habituating the study groups, and R. Kaserengenyu, S. Katusabe, R. Sabiiti, and P. Irumba for assistance in the field. In addition, we are grateful to $\mathrm{M}$. Grote for help with statistical analyses, to A. Marshall, A. Harcourt, and two anonymous reviewers for helpful comments on earlier drafts of this manuscript, and to the UC Davis students who helped digitize the data. This study complied with the current laws of Uganda.

Open Access This article is distributed under the terms of the Creative Commons Attribution Noncommercial License which permits any noncommercial use, distribution, and reproduction in any medium, provided the original author(s) and source are credited.

\section{References}

Adams ES (2005) Bayesian analysis of dominance hierarchies. Anim Behav 69:1191-1201

Alexander RD (1974) The evolution of social behavior. Annu Rev Ecol Syst 5:324-383

Appleby MC (1983) The probability of linearity in hierarchies. Anim Behav 31:600-608

Archie EA, Morrison TA, Foley CAH, Moss CJ, Alberts SC (2006) Dominance rank relationships among wild female African elephants, Loxodonta africana. Anim Behav 71:117-127

Barrett L, Henzi SP, Weingrill T, Lycett JE, Hill RA (1999) Market forces predict grooming reciprocity in female baboons. Proceedings of the Royal Society of London, Series B 266:665-670

Barton RA, Whiten A (1993) Feeding competition among female olive baboons, Papio anubis. Anim Behav, 46:777-789

Boinski S, Sughrue K, Selvaggi L, Quatrone R, Henry M, Cropp S (2002) An expanded test of the ecological model of primate social evolution: competitive regimes and female bonding in three species of squirrel monkeys (Saimiri oerstedii, S. boliviensis, and S. sciureus). Behaviour 139:227-261

Borries C (1993) Ecology of female social relationships: hanuman langurs (Presbytis entellus) and the van Schaik model. Folia Primatol 61:21-30

Bradley RA, Terry ME (1952) Rank analysis of incomplete block designs. I. The method of paired comparisons. Biometrika 39:324-345

Busse C (1982) Social dominance and offspring mortality among female chacma baboons. Int J Primatol 3:267 
Byrne RW, Whiten A, Henzi SP (1989) Social relationships of mountain baboons: leadership and affiliation in a non-femalebonded monkey. Am J Primatol 18:191-207

Chancellor RL, Isbell LA (2008) Punishment and competition over food in captive rhesus macaques (Macaca mulatta). Anim Behav 75:1939-1947

Chapais B (1992) The role of alliances in social inheritance of rank among female primates. In: Harcourt AH, de Waal FBM (eds) Coalitions and alliances in humans and other animals. Oxford Science, Oxford, pp 29-59

Chapais B, Gauthier C, Prud'homme J, Vasey P (1997) Relatedness threshold for nepotism in Japanese macaques. Anim Behav 53:1089-1101

Chapman CA, Chapman LJ (2000) Constraints on group size in red colobus and red-tailed guenons: examining the generality of the ecological constraints model. Int J Primatol 21:565-585

Chapman CA, Wrangham RW, Chapman LJ (1995) Ecological constraints on group size: an analysis of spider monkeys and chimpanzee subgroups. Behav Ecol Sociobiol 36:59-70

Chapman CA, Chapman LJ, Wrangham R, Isabirye-Basuta G, BenDavid K (1997) Spatial and temporal variability in the structure of a tropical forest. Afr J Ecol 35:341-436

Cords M (2000) The agonistic and affiliative relationships of adult females in a blue monkey group. In: Whitehead P, Jolly C (eds) Old world monkeys. Cambridge University Press, Cambridge, pp 453-479

Cords M (2002) Friendship among adult female blue monkeys (Cercopithecus mitis). Behaviour 139:291-314

Dunbar RIM (1980) Determinants and evolutionary consequences of dominance among female gelada baboons. Behav Ecol Sociobiol 7:253-265

Eisner T, Eisner M, Rossini C, Iyengar VK, Roach BL, Benedikt E, Meinwald J (2000) Chemical defense against predation in an insect egg. Proc Natl Acad Sci U S A 97:1634-1639

Fossey D, Harcourt AH (1977) Feeding ecology of free ranging mountain gorilla (Gorilla gorilla beringei). In: Clutton-Brock TH (ed) Primate ecology. Academic, London, pp 415-447

Fournier F, Festa-Bianchet M (1995) Social dominance in adult female mountain goats. Anim Behav 49:1449-1459

Freeland WJ (1979) Mangabey (Cercocebus albigena) social organization and population density in relation to food use and availability. Folia Primatol 32:108-124

Gemmill A, Gould L (2008) Microhabitat variation and its effects on dietary composition and intragroup feeding interactions between adult female Lemur catta during the dry season at Beza Mahafaly Special Reserve, southwestern Madagascar. Int J Primatol 29:1511-1533

Gill J (2002) Bayesian methods: a social and behavioral science approach. Chapman \& Hall, Boca Raton

Harcourt AH, Stewart KJ (2007) Gorilla society: conflict, compromise, and cooperation between the sexes. University of Chicago Press, Chicago

Harris EE (2000) Molecular systematics of the Old World monkey tribe Papionini: analysis of the total available genetic sequences. J Hum Evol 38:235-256

Hausfater G, Altmann J, Altmann S (1982) Long-term consistency of dominance relations among female baboons (Papio cynocephalus). Science 217:752-754

Hill DA, Okayasu N (1995) Absence of "youngest ascendancy" in the dominance relations of sisters in wild Japanese macaques (Macaca fuscata yakui). Behaviour 132:367-379

Ingold P, Marbacher H (1991) Dominance relationships and competition for resources among chamois Rupicapra rupicapra rupicapra in female social groups. Z Saugetierkd 56:88-93

Isbell LA (1983) Daily ranging behavior of red colobus (Colobus badius tephrosceles) in Kibale Forest, Uganda. Folia Primatol 41:34-48
Isbell LA (1991) Contest and scramble competition: patterns of female aggression and ranging behavior among primates. Behav Ecol 2:143-155

Isbell LA (1998) Diet for a small primate: insectivory and gummivory in the (large) patas monkey (Erythrocebus patas pyrrhonotus). Am J Primatol 45:381-398

Isbell LA, Pruetz JD (1998) Differences between vervets (Cercopithecus aethiops) and patas monkeys (Erythrocebus patas) in agonistic interactions between adult females. Int J Primatol 19:837-855

Isbell LA, Young TP (2002) Ecological models of female social relationships in primates: similarities, disparities, and some directions for future clarity. Behaviour 139:177-202

Isbell LA, Young TP (2007) Interspecific and temporal variation of ant species within Acacia drepanolobium ant domatia, a staple food of patas monkeys (Erythrocebus patas) in Laikipia, Kenya. Am J Primatol 69:1387-1398

Isbell LA, Pruetz JD, Young TP (1998) Movements of vervets (Cercopithecus aethiops) and patas monkeys (Erythrocebus patas) as estimators of food resource size, density, and distribution. Behav Ecol Sociobiol 42:123-133

Isbell LA, Pruetz JD, Lewis M, Young TP (1999) Rank differences in ecological behavior: a comparative study of patas monkeys (Erythrocebus patas) and vervets (Cercopithecus aethiops). Int J Primatol 20:257-272

Janson CH (1985) Aggressive competition and individual food consumption in wild brown capuchin monkeys (Cebus apella). Behav Ecol Sociobiol 18:125-138

Janson CH (1990) Ecological consequences of individual spatial choice in foraging groups of brown capuchin monkeys, Cebus apella. Anim Behav 40:922-934

Janson CH, Goldsmith ML (1995) Predicting group size in primates: foraging costs and predation risks. Behav Ecol 6:326-336

Knott CD (1998) Changes in orangutan caloric intake, energy balance, and ketones in response to fluctuating fruit availability. Int $\mathrm{J}$ Primatol 19:1061-1079

Koenig A, Borries C (2006) The predictive power of socioecological models: a reconsideration of resource characteristics, agonism, and dominance hierarchies. In: Hohmann G, Robbins MM, Boesch C (eds) Feeding ecology in apes and other primates. Ecological, physical and behavioral aspects. Cambridge University Press, Cambridge, pp 263-284

Krall BS, Bartelt RJ, Lewis CJ, Whitman DW (1999) Chemical defense in the stink bug Cosmopepla bimaculata. J Chem Ecol 25:2477-2494

Lambert JE, Chapman CA, Wrangham RW, Conklin-Brittain NL (2004) Hardness of cercopithecine foods: implications for the critical function of enamel thickness in exploiting fallback foods. Am J Phys Anthropol 125:363-368

Mathy J, Isbell LA (2001) The relative importance of size of food and interfood distance in eliciting aggression in captive rhesus macaques (Macaca mulatta). Folia Primatol 72:268-277

Menard N, Qarro M (1999) Bark stripping and water availability: a comparative study between Moroccan and Algerian Barbary macaques (Macaca sylvanus). Rev Ecol-Terre Vie 54:123-132

Mitchell CL, Boinski S, van Schaik CP (1991) Competitive regimes and female bonding in two species of squirrel monkeys (Saimiri oerstedi and S. sciureus). Behav Ecol Sociobiol 28:55-60

Murray CM, Eberly LE, Pusey AE (2006) Foraging strategies as a function of season and rank among wild female chimpanzees (Pan troglodytes). Behav Ecol 17:1020-1028

Olupot W (1998) Long-term variation in mangabey (Cercocebus albigena johnstoni Lydekker) feeding in Kibale National Park, Uganda. Afr J Ecol 36:96-101

Olupot W, Waser PM (2001) Activity patterns, habitat use and mortality risks of mangabey males living outside social groups. Anim Behav 61:1227-1235 
Olupot W, Waser PM, Chapman CA (1998) Mangabey (Lophocebus albigena) fruit finding: are monitoring of fig trees and use of sympatric loud frugivore calls possible strategies? Int J Primatol 19:339-353

Parker GA (1974) Assessment strategy and the evolution of fighting behaviour. J Theor Biol 47:223-243

Payne HFP, Lawes MJ, Henzi SP (2003) Competition and the exchange of grooming among female samango monkeys (Cercopithecus mitis erythrarchus). Behaviour 140:453-471

Post DG, Hausfater G, McCuskey SA (1980) Feeding behavior of yellow baboons (Papio cynocephalus): relationship to age, gender and dominance rank. Folia Primatol 34:170-195

Pruetz JD, Isbell LA (2000) Correlations of food distribution and patch size with agonistic interactions in female vervets (Chlorocebus aethiops) and patas monkeys (Erythrocebus patas) living in simple habitats. Behav Ecol Sociobiol 49:38-47

Pulliam HR, Caraco T (1984) Living in groups: is there an optimal group size? In: Krebs JR, Davies NB (eds) Behavioural ecology: an evolutionary approach, 2nd edn. Sunderland, Massachusetts, Sinauer, pp 122-147

Pusey AE, Williams J, Goodall J (1997) The influence of dominance rank on the reproductive success of female chimpanzees. Science 277:828-831

Range F, Noë R (2002) Familiarity and dominance relations among female sooty mangabeys in the Taï National Park. Am J Primatol $56: 137-153$

Rogers E, Tutin C, Parnell R, Voysey B, Fernandez M (1994) Seasonal feeding on bark by gorillas: an unexpected keystone food? In: Abstracts from the XIVTH Congress of the Int Primatol Society. IPS, Strasbourg, p 154

Ron T, Henzi SP, Motro U (1996) Do female chacma baboons compete for a safe spatial position in a southern woodland habitat? Behaviour 133:475-490

Rothman JM, van Soest PJ, Pell AN (2006) Decaying wood is a sodium source for mountain gorillas. Biol Lett 2:321-324

Saito C (1996) Dominance and feeding success in female Japanese macaques, Macaca fuscata: effects of food patch size and interpatch distance. Anim Behav 51:967-980

Seyfarth RM (1976) Social relationships among adult female baboons. Anim Behav 24:917-938

Seyfarth RM (1980) The distribution of grooming and related behaviours among adult female vervet monkeys. Anim Behav 28:798-813

Silk JB, Seyfarth RM, Cheney DL (1999) The structure of social relationships among female savanna baboons in Moremi Reserve, Botswana. Behaviour 136:679-703

Silk JB, Alberts SC, Altmann J (2004) Patterns of coalition formation by adult female baboons in Amboseli, Kenya. Anim Behav 67:573-582

Sillén-Tullberg B, Leimar O (1988) The evolution of gregariousness in distasteful insects as a defense against predators. Am Nat 132:723-734

Skorupa JP (1988) The effect of selective timber harvesting on rainforest primates in Kibale Forest, Uganda. Ph.D. Dissertation. University of California, Davis

Smith RD, Ruxton GD, Cresswell W (2001) Dominance and feeding interference in small groups of black birds. Behav Ecol 4:475-481

Snaith TV, Chapman CA (2005) Towards an ecological solution to the folivore paradox: patch depletion as an indicator of within-group scramble competition in red colobus. Behav Ecol Sociobiol 59:185-190

Spiegelhalter D, Thomas A, Best N, Lunn D (2003) WinBUGS user manual, version 1.4. MRC Biostatistics Unit, Cambridge

Sterck EHM, Watts DP, van Schaik CP (1997) The evolution of female social relationships in nonhuman primates. Behav Ecol Sociobiol 41:291-309

Struhsaker TT (1975) The red colobus monkey. University of Chicago Press, Chicago

Struhsaker TT (1997) Ecology of an African rain forest. University Press of Florida, Gainesville

Tosi AJ, Disotell TR, Morales JC, Melnick DJ (2003) Cercopithecine Y-chromosome data provide a test of competing morphological evolutionary hypotheses. Mol Phylogenet Evol 27:510-521

Trivers RL (1972) Parental investment and sexual selection. In: Campbell B (ed) Sexual selection and the descent of man, 18711971. London, Aldine, pp 136-179

van Hooff JARAM, Wensing JAB (1987) Dominance and its behavioral measures in a captive wolf pack. In: Frank HW (ed) Man and wolf: advances, issues, and problems in captive wolf research. Junk, Dordrecht, pp 219-252

van Noordwijk MA, van Schaik CP (1987) Competition among female long-tailed macaques, Macaca fascicularis. Anim Behav 35:577-589

van Schaik CP (1989) The ecology of social relationships amongst female primates. In: Standen V, Foley RA (eds) Comparative socioecology. Blackwell Scientific, London, pp 195-218

van Schaik CP, van Noordwijk MA (1988) Scramble and contest in feeding competition among female long-tailed macaques (Macaca fascicularis). Behaviour 105:77-98

Vehrencamp SL (1983) A model for the evolution of despotic versus egalitarian societies. Anim Behav 31:667-682

Vervaecke H, Roden C, De Vries H (2005) Dominance, fatness and fitness in female American bison, Bison bison. Anim Behav 70:763-770

Vogel ER (2005) Rank difference in energy intake rates in white-faced capuchin monkeys, Cebus capucinus: the effects of contest competition. Behav Ecol Sociobiol 58:333-444

Vogel ER, Janson CH (2007) Predicting the frequency of food related agonism in white-faced capuchin monkeys (Cebus capucinus), using a novel focal tree method. Am J Primatol 69:533-550

Walters JR, Seyfarth RM (1987) Conflict and cooperation. In: Smuts BB, Cheney DL, Seyfarth RM, Wrangham RW (eds) Primate societies. University of Chicago Press, Chicago, pp 306-317

Waser PM (1975) Monthly variations in feeding and activity patterns of the mangabey, Cercocebus albigena (Lyddeker). E Afr Wildl J $13: 249-263$

Waser PM (1977) Feeding, ranging and group size in the mangabey Cercocebus albigena. In: Clutton-Brock TH (ed) Primate ecology. Academic, London, pp 183-222

Waser PM (1978) Postreproductive survival and behavior in a freeranging female mangabey. Folia Primatol 29:142-160

Waser PM, Floody O (1974) Ranging patterns of the mangabey Cercocebus albigena, in the Kibale Forest, Uganda. Z Tierpsychol 35:2-101

Wrangham RW (1980) An ecological model of female-bonded primate groups. Behaviour 75:262-300 